\title{
Direct Democracy and the Politics of Abortion: Evaluating the Responsiveness of State Abortion Policy to State Abortion Attitudes
}

\author{
By Samantha E. Holquist
}

In 1993, researchers began to explore whether public policies in states with initiative and referendum mechanisms are more responsive to public opinion than in those states that do not have such mechanisms. There is yet no conclusive answer to this question. To examine this relationship, I add to the work of Kevin Arceneaux's 2002 study, which utilizes public opinion data to analyze the responsiveness of state abortion policies to citizen abortion attitudes in states with and without initiatives and referendums. Additionally, my analysis looked to differentiate policy responsiveness along the lines of how difficult the implementation environment is within a state. My results showed that there is stronger responsiveness to public opinion in direct democracy states as contrasted to states with no initiative and referendum procedures. Further, I found measured statistical differences within direct democracy states when contrasting easy and difficult implementation procedures.

\section{Introduction}

Direct democracy is now a fundamental element of American governance. Spreading throughout the nation during the Progressive Era, direct democracy developed out of citizen distrust of political elites and government institutions. Its primary aim is to constrain unpopular actions by state legislatures. Twenty-three states allow initiative and referendum mechanisms (Walters 2003). An initiative is a measure placed on the ballot or legislative agenda that is proposed by the citizens. A referendum is a vote by the citizens to accept, reject, or repeal a proposal, such as a constitutional amendment or law. According to public opinion surveys, 70 percent of the nation's population supports direct democracy at the state and local level (Matsusaka 2005). While direct democracy is more prevalent west of the Mississippi, each region of the country contains at least a few direct democracy states. Beginning in 1977, citizen use of the initiative and referendum process has reflected increased acceptance; usage is up about 164 percent since 1898 when South Dakota first adopted the process (Ernst 2001). This increase is especially notable with initiatives concerning abortion.

Abortion has been on the national debate agenda since the 1973 Roe $v$. Wade Supreme Court decision, which removed restrictions on a woman's right to terminate a pregnancy in the first trimester and with limited restrictions in the second trimester (Fiorina, Abrams, and Pope 2010). States have primary jurisdiction over abortion law, and from 1972 to 2000, 24 initiatives and referendums pertaining to abortion were placed on the ballot (Walters 2003).

The twenty-first century has seen both increased legal challenges and increased referendum activity related to abortion. The 2000 Stenberg $v$. Carhart case held that partial-birth abortion was legal. In 2007, the US Supreme Court in Gonzales $v$. Carhart overturned the 2000 
decision and upheld the 2003 Partial-Birth Abortion Ban Act (Fiorina et al. 2010). Fourteen abortion initiative and referendum questions have been posed to voters since 2000. A summary of initiative and referendum activity regarding abortion since 1972 is shown in Table 1 below. Of the total 37 actions, Colorado and Oregon account for eight and five, respectively.

An integral part of American moral opinion and policy, abortion is an ideal area to analyze direct democracy's impacts on policy responsiveness to public opinion (Arceneaux 2002). Because abortion is a highly controversial and less technical issue, people are more likely to form strong opinions and feel knowledgeable enough to participate in the political debate (Mooney and Lee 1995). Arceneaux finds that "citizens are more likely to care if abortion policy is unresponsive, and direct democracy may help translate abortion preferences into policy" (Arceneaux 2002, 374). States with initiative and referendum mechanisms, especially those with easy implementation, should produce abortion policies that align closely with public attitudes. Said another way, direct democracy states should demonstrate congruency between their citizens' opinions on abortion and how restrictive their corresponding laws are regarding abortion, and states without initiative and referendum procedures are likely not to be as responsive in abortion policy-making.

Based on these assertions, I hypothesized that there exists a difference in the responsiveness of public policy to public opinion between states with and without initiative and referendum mechanisms. I also hypothesized that there is a significant difference in abortion policy responsiveness between initiative and referendum states with easy implementation procedures when contrasted against those with more difficult implementation procedures. I used several bivariate analysis techniques, specifically congruency scores, coefficients of determination $\left(\mathrm{R}^{2}\right)$, and variance, to test these hypotheses on state-by-state data pertaining to abortion restrictiveness, abortion attitude, existence or lack thereof of initiative and referendum mechanisms, and ease of implementing these mechanisms.

\section{The Direct Democracy Debate}

There are many debates about direct democracy, such as whether it promotes minority rights violations or special-interest dominance; however, in recent years, the most prominent debate about direct democracy has focused on whether it enhances congruency between public policy and public attitude. In this section, I review the main arguments offered by both proponents and detractors of direct democracy. Although there has been substantial empirical research conducted within this debate, there is limited work on social issues, such as abortion. Additional research is warranted to better understand direct democracy's impact on policy congruence regarding such social issues.

Opponents argue that direct democracy subverts the public will and does not promote the political participation that would lead to congruence between policy and public opinion (Lascher, Hagen, and Rochlin 1996). In Culture War?: The Myth of Polarized America, Morris Fiorina, Samuel Abrams, and Jeremy Pope conclude that very few citizens actually utilize direct democracy; those that do participate tend to have extremely polarized views. Extreme views tend to dominate the political and policy debate over moral issues, especially those concerning abortion and gay rights (2010).

Regarding the initiative and referendum process, some opponents believe that multiple proposals on a single issue, bundled proposals on a ballot, and lack of information about the ballot all ultimately distort the public will (Saari and Sieberg 2001). Multiple proposals "may push or pull voters at the margins enough to construct majorities on individual proposals that would not have been approved if all the proposals had been bundled" 
Table 1: Abortion Related U.S. Initiatives and Referendums 1972-2013

\begin{tabular}{|c|c|c|c|c|c|c|}
\hline Year & State & Proponent & Description & Yes (\%) & No (\%) & Pass/ \\
\hline 1972 & MI & Pro-Choice & Make abortion legal & $39 \%$ & $61 \%$ & Fail \\
\hline 1972 & ND & Pro-Choice & Make abortion legal & $23 \%$ & $77 \%$ & Fail \\
\hline 1978 & OR & Pro-Life & Restrict State Funding & $48 \%$ & $52 \%$ & Fail \\
\hline 1982 & $\mathrm{AK}$ & Pro-Life & Restrict State Funding & $41 \%$ & $59 \%$ & Fail \\
\hline 1984 & $\mathrm{CO}$ & Pro-Choice & Restore State Funding & $50.39 \%$ & $49.61 \%$ & Pass \\
\hline 1984 & WA & Pro-Life & Restrict State Funding & $47 \%$ & $53 \%$ & Fail \\
\hline 1986 & $\mathrm{AR}$ & Pro-Life & Restrict State Funding & $49.96 \%$ & $50.04 \%$ & Fail \\
\hline 1986 & MA & Pro-Life & Restrict State Funding & $42 \%$ & $58 \%$ & Fail \\
\hline 1986 & OR & Pro-Life & Restrict State Funding & $45 \%$ & $55 \%$ & Fail \\
\hline 1986 & RI & Pro-Life & Restrict State Funding & N/A & N/A & Fail \\
\hline 1988 & $\mathrm{AR}$ & Pro-Life & Restrict State Funding & $52 \%$ & $48 \%$ & Pass \\
\hline 1988 & $\mathrm{CO}$ & Pro-Choice & Restore State Funding & $40 \%$ & $60 \%$ & Fail \\
\hline 1988 & MI & Pro-Life & Restrict State Funding & $57 \%$ & $43 \%$ & Pass \\
\hline 1990 & OR & Pro-Life & Make illegal w/exceptions & $32 \%$ & $68 \%$ & Fail \\
\hline 1990 & OR & Pro-Life & Parental Notice & $48 \%$ & $52 \%$ & Fail \\
\hline 1991 & WA & Pro-Choice & Codify Roe v. Wade & $50.10 \%$ & $49.90 \%$ & Pass \\
\hline 1992 & $\mathrm{AZ}$ & Pro-Life & Limit w/exceptions & $31 \%$ & $69 \%$ & Fail \\
\hline 1992 & $\mathrm{MD}$ & Pro-Choice & Codify Roe v. Wade & $62 \%$ & $38 \%$ & Pass \\
\hline 1996 & $\mathrm{CO}$ & Pro-Life & Parental Notice & $42 \%$ & $58 \%$ & Fail \\
\hline 1998 & $\mathrm{CO}$ & Pro-Life & Partial Birth Abortion Ban & $48 \%$ & $52 \%$ & Fail \\
\hline 1998 & $\mathrm{CO}$ & Pro-Life & Parental Notice & $55 \%$ & $45 \%$ & Pass \\
\hline 1998 & WA & Pro-Life & Partial Birth Abortion Ban & $43 \%$ & $57 \%$ & Fail \\
\hline 1999 & ME & Pro-Life & Partial Birth Abortion Ban & $45 \%$ & $55 \%$ & Fail \\
\hline 2000 & $\mathrm{CO}$ & Pro-Life & Waiting Period & $40 \%$ & $60 \%$ & Fail \\
\hline 2004 & FL & Pro-Life & Parental Notice & $65 \%$ & $35 \%$ & Pass \\
\hline 2005 & $\mathrm{CA}$ & Pro-Life & Parental Notice & $47 \%$ & $53 \%$ & Fail \\
\hline 2006 & $\mathrm{CA}$ & Pro-Life & Parental Notice & $46 \%$ & $54 \%$ & Fail \\
\hline 2006 & OR & Pro-Life & Parental Notice & $45 \%$ & $55 \%$ & Fail \\
\hline 2006 & $\mathrm{SD}$ & Pro-Choice & Abortion Ban (veto ref.) & $44 \%$ & $56 \%$ & Fail \\
\hline 2008 & CA & Pro-Life & Parental Notice & $48 \%$ & $52 \%$ & Fail \\
\hline 2008 & $\mathrm{CO}$ & Pro-Life & Fetal Personhood & $27 \%$ & $73 \%$ & Fail \\
\hline 2008 & SD & Pro-Life & Abortion Ban & $45 \%$ & $55 \%$ & Fail \\
\hline 2010 & AK & Pro-Life & Parental Notice & $55 \%$ & $45 \%$ & Pass \\
\hline 2010 & $\mathrm{CO}$ & Pro-Life & Fetal Personhood & $30 \%$ & $70 \%$ & Fail \\
\hline 2011 & MS & Pro-Life & Fetal Personhood & $42 \%$ & $58 \%$ & Fail \\
\hline 2012 & FL & Pro-Life & Restore State Funding & $45 \%$ & $55 \%$ & Fail \\
\hline 2012 & MT & Pro-Life & Parental Notice & $71 \%$ & $29 \%$ & Pass \\
\hline
\end{tabular}

Source: Waters 2003, Ballotpedia 2014. 
(Arceneaux 2002, 375). To critics, multiple proposals lead to disjointed policies on underlying issues and undermine the public's desires. Similarly, bundled proposals may contain many components with which the median voters do not agree; however, the voters approve the ballot measure because they agree with the majority of the proposals. As a result, a portion of the population may become frustrated with policies, which may not accurately reflect their opinions (Saari and Sieberg 2001). Opponents contend that the median voter is not represented when direct democracy is present; as a consequence, public opinion and public opinion policy become misaligned and incongruent.

Direct democracy proponents argue that state policy-making is influenced for the better in two ways: (1) directly, by allowing the public to vote on initiatives and referendums, and (2) indirectly, by persuading elected officials to choose policy alternatives that avert ballot proposals. They argue that direct democracy produces more congruency between public policy and public opinion because it pushes policy closer to the median voter and forces the legislature to anticipate the desires of the constituency (Gerber 1996; Matsusaka 2005). Within initiative and referendum states, legislatures must anticipate and respond to public opinion to avoid being completely undermined by citizen-driven law initiatives. By anticipating future initiatives, legislatures can also prevent citizens from voting on inadequate or ineffective laws by drafting initiative details before citizen activists or special interest groups can craft them (Gerber 1996).

Both John Matsusaka and Eliza-

beth Gerber argue that the presence of initiatives and referendums in a state substantially increase the congruency between state public policy and public opinion.

Further, they find that interest groups affect policy across all states, not just direct democracy states (Gerber 1996; Matsusaka 2005). As a reaction against interest groups, direct democracy helps control legislative agendas and forces legislatures to focus on issues that are important to the majority of the people (Matsusaka 2005). Initiatives and referendums give legislatures a more accurate depiction of voter opinion and views on important policies, such as those regarding fiscal issues (Bowler and Donovan 2004). Citizens are more likely to participate in the political process if the issues up for legislative attention are considered by the public electorate to be of interest and worthy of consideration. In these circumstances, the median voter is likely to be more represented at the voting booth, leading to policies more congruent with overall public opinion.

Contradicting the claim that voters are too incompetent to make sophisticated decisions by ballot, Arthur Lupia finds that voters use information shortcuts to make competent choices. Voters use the information they know to analyze measures, a very similar process to that used in the legislatures. When information on a measure is sparse or lacking, voters typically opt against it (Lupia 2001; Lupia and Matsusaka 2004). Many voters use their own underlying values and interests to make sense of ballot measures; as a result, their votes are often the same as they would have been with substantially more information (Lupia and Matsusaka 2004). A lack of information does not significantly alter the median voter's opinion on a measure; therefore, approved measures are not necessarily incongruent with public attitude. This is especially true for the highly salient issue of abortion, where individuals are more likely to be knowledgeable about the subject (Arceneaux 2002).

Some scholars simply conclude that "government policy is no more responsive to the electorate's preferences in states where ballot initiatives are permitted than in states where they are not" (Hagen, Lascher, and Camobreco 2001, 1257). They find that current research fails to definitively prove that initiative and referendum states are doing a better job at complying with constituents' desires. 


\section{A Need for Further Research}

As mentioned above, substantial empirical research exists that tests the responsiveness of state policy to public opinion; however, there is limited recent research dealing with social issues, such as abortion. Arceneaux's research specifically studied the responsiveness of state abortion policies to citizen abortion attitudes in states with and without initiatives and referendums. In his research, Arceneaux excludes 10 states due to lack of state-level public opinion data, and he utilizes data through 2002 (Arceneaux 2002). In contrast, this analysis included data through 2010 from all 50 states, thus providing the opportunity for a more comprehensive view of direct democracy's impacts on state abortion policy responsiveness to state abortion public opinion.

Matsusaka's 2010 study is the most recent addition to the empirical research on direct democracy's responsiveness. His work addressed social issues, including abortion; however, it only included public opinion data through 2004 and only analyzed state policy data through 2006 (Matsusaka 2010). As public opinion becomes more stable on the abortion issue, especially in recent years, new research must be conducted on the responsiveness of state abortion policy to state abortion attitude (Fiorina et al. 2010). For this study, I added a new dimension to the empirical research by analyzing relationships between state abortion policy and public opinion in both easy and difficult implementation direct democracy states (i.e., those with initiatives and referendum). Bowler and Donovan last conducted their research regarding implementation procedure influences in 2004. In their work, they did not consider social issues (Bowler and Donovan 2004). With my research approach, I have attempted to extend and improve the body of empirical research on direct democracy and the politics of abortion.

\section{Data}

Scholars continue to produce different alternatives to empirically measure state responsiveness to public opinion. I selected a framework that is relatively simplistic and similar to the majority of the research models discussed in the literature (Arceneaux 2002; Bowler and Donovan 2004; Gerber 1996; Hagen et al. 2001; Matsusaka 2001, 2005, 2010).

\section{Measuring Attitude and Responsiveness}

For my analysis of direct democracy's influence on state abortion policy, I selected "state abortion attitude" as the independent variable. I used measures of "state abortion policy restrictiveness" as the dependent variable. This is a logical approach in my attempt to explore relationships between opinions held by citizens and actions taken by their state governments as my variable selection mirrored approaches used in past scholarly research on the impacts of direct democracy.

To measure state abortion attitude, I used a 2005 nationwide survey conducted by SurveyUSA, which asked individuals if they were pro-choice, pro-life, or not sure (SurveyUSA 2005). SurveyUSA interviewed voting-age adults (ages 18 or above) via phone in each of the 50 states from August 12, 2005 to August 14, 2005. Responses were tallied by state. I used the percentage of individuals from each state that answered pro-life as the measure for state abortion attitude. The increasing percentages indicated stronger pro-life views among the state's citizenry; that is, they were more likely to support legalized restrictions on abortion.

Unlike previous researchers on this topic, I constructed a "State Abortion Policy Restrictiveness Index" based on variables reflecting data produced by the Guttmacher Institute related to state abortion legislation and regulation (Guttmacher Institute 2010). Many political theorists use the National Abortion Action League (NARAL) index, which 
scores states on fourteen categories of legal restrictions on abortion access (Arceneaux 2002; Brace et al. 2002; Gerber 1996; Matsusaka 2010). However, I did not believe this provided a comprehensive measurement of state abortion policy restrictiveness.

As shown in Appendix 1, my state abortion policy restrictiveness percentage was calculated from twelve categories. I did not include eight categories from NARAL in the index and primarily deleted three of these-unenforceable abortion ban, prohibitions on clinic violence, and spousal consent-because I determined that they no longer play a prominent role in state abortion policy, as many states have already enacted these types of policies (Guttmacher Institute 2010). The policy restrictive percentage is determined by dividing the number of restrictions applicable in each state by its total number of possible restrictions. The higher the restrictiveness percentage, the more restrictive is a state's abortion policy as reflected in legislation or regulation.

\section{Observation Groupings: Initiative and} Referendum $(I / R)$ and Non-I/R States; Easy and Difficult Implementation

To further explore the relationship between abortion attitudes (based on polling) and restrictiveness (measured through legislation), I segregated the total national set of observations into smaller groupings based on direct democracy features. These groupings are: (1) non-initiative and referendum states (non-I/R states), (2) initiative and referendum states (I/R states), (3) easy implementation I/R states, and (4) difficult implementation I/R states. Methodology for assembling these groupings is discussed below.

Using the 2003 Initiative and Referendum Almanac, I divided the states into two categories: non-I/R states and I/R states (Walters 2003). Unlike many political researchers studying state responsiveness using social issues variables, I included all 50 states in the data (Arceneaux 2002; Brace et al. 2002). Twenty-three states are categorized as I/R states and the remaining 27 are categorized as non-I/R states. I further split I/R states into two sub-categories: easy implementation states and difficult implementation states.

Following the research model utilized by Bowler and Donovan, I constructed the "Implementation Difficulty Index," which measures the difficulty of placing an initiative or referendum proposition on the ballot as well as the ability of the legislature to influence its contents and form (Bowler and Donovan 2004). I combined portions of Bowler and Donovan's "Qualification Difficult Index" and "Legislative Insulation Index" to create the Implementation Difficulty Index. The Implementation Difficulty Index may be a better representation of the difficulty of implementing an initiative and referendum because it combines all areas of the process.

As seen in Appendix 2, I/ $\mathrm{R}$ restrictiveness can be calculated using a number of variables, ranging from restrictions on signature requirements to limits on direct statues depending on the state (Walters 2003). In constructing the Implementation Difficulty Index, I used signature requirements and deadline for submission to calculate restrictiveness because the higher number of signatures and the earlier the citizens must submit the measure make it more difficult to place the measure on the ballot. Also, I utilized geographic distribution because it may make it more difficult if citizens must get signatures from different areas of the state. Further, I used indirect constitutional amendments and statues limitations because they allow the legislature to enact, amend, or reject the measure before it is placed on the ballot. Finally, I utilized legislators' ability to amend or repeal statutory initiatives because this allows the legislature to change the initiative after the voters approve it. 
After determining the number of restrictions within the state, I divided this number by the overall possible number of restrictions to obtain the percentage of implementation restrictiveness. Alaska, Idaho, Maine, Utah, Washington, and Wyoming were only calculated out of six because they have a statute-only limitation, while Florida and Mississippi were only calculated out of 10 because they have a constitutional amendment-only limitation. The overall mean percentage of implementation restrictiveness is 46 percent, serving as a baseline for determining easy implementation versus difficult implementation in I/R states. Those states with percentages below 46 percent are categorized as easy implementation I/R states, while those above are categorized as difficult implementation I/R states. Using this methodology, I determined that 14 states fall in the difficult implementation category, while nine may be viewed as having easy implementation features.

\section{Analysis Methods and Results}

In exploring the relationship

between abortion attitude and policy response, I used several bivariate methods to study this correlation, including histo- grams, scatter plots, linear regressions, and variance measures. My aim was to provide further evidence to suggest a potential congruence between public opinion and resulting legislative actions in states with and without direct democracy procedures.

\section{Congruence Score Analysis}

For my initial analysis, I calculated "congruence scores" for each state grouping in order to construct a histogram. By contrasting these values, I was able to visualize the congruency of policy to attitudes across the various direct democracy and non-direct democracy states. To calculate state-level congruence scores, I ranked the states from one to 50 according to each state's percent policy restrictiveness, with one being the most restrictive and 50 being the least restrictive. I repeated the ranking process for the state's percent public opinion pro-life, with one being the most pro-life and 50 being the least. Where there were ties among states in percent policy restrictiveness or percent public opinion pro-life, the tied states each received the same ranking and the following states received a lower ranking based on how many states were tied. For

Figure 1: Congruence Score Comparison of Abortion Policy Restrictiveness to State Abortion Attitude by State Groupings

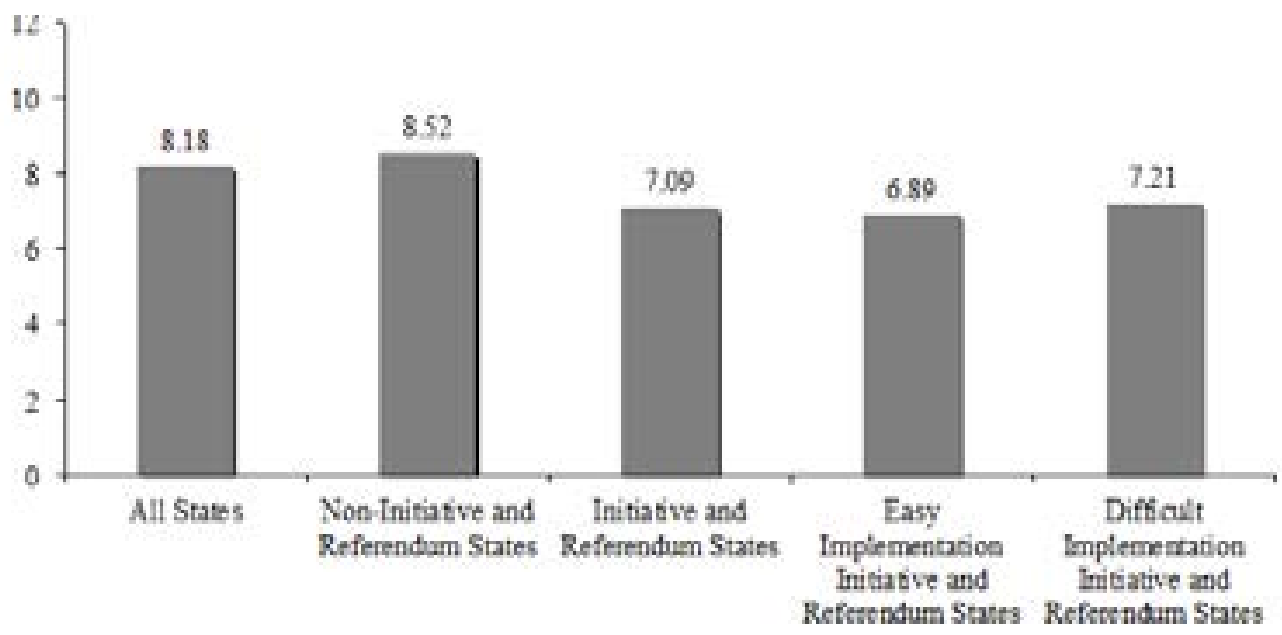


instance, in percent policy restiveness, Missouri, Oklahoma, and North Dakota each received a ranking of one, as each state was 92 percent restrictive, while the next most restrictive state, Kansas, with 83 percent policy restrictiveness, received a ranking of 4 . For each state, I determined any ranking differences by subtracting and taking the absolute values of its rank values. For example, Alabama had a percent policy restrictiveness ranking of 19 and a percent pro-life opinion ranking of 5 , creating a statelevel congruence score of 14 .

As a final step in analyzing congruence scores, I calculated the mean of the state-level congruence scores for each state subgrouping (non-I/R states, I/R states, easy implementation I/R states, and difficult implementation I/R states). These subgrouping means are the state grouping congruence scores, and they were contrasted to provide a sense of how aligned abortion policy is to public opinion. A lower value indicated more congruence. A histogram detailing all congruence scores is shown in Figure 1 (on prior page). These results can be interpreted as follows:
1. Scores for all groupings were well above the perfect congruence score of zero, which indicated substantial differences in responsiveness to opinion. Scores ranged from 8.52 to 6.89 .

2. With overall lower scores, the I/R states demonstrated closer congruence than non(I/R) states.

3. There was only a small difference between easy and difficult implementation (I/R) states.

4. Easy implementation states demonstrated the lowest congruence score, demonstrating the strongest congruence between policy restrictiveness and abortion attitude.

\section{Regression Analysis}

I next displayed my state-bystate data observations between abortion attitude and policy restrictiveness measures on two-dimensional scatter plot graphs. My independent variable, abortion attitude, is shown on the x-axis; my dependent variable, policy restrictiveness, is shown on the $y$-axis. The purpose of this was to demonstrate whether a positive relationship exists between policy restrictiveness and pro-life opinion in my data set, and if so, what form it takes. However, even when a scatter plot shows an association between variables, there is not necessarily a causal relationship.

To further assist in understanding these relationships, I used ordinary least squares regression to indicate any observable abortion opinion-policy congruency. Using the scatter plots mentioned above, I fit each data grouping on these plots with regression lines using ordinary least squares regression. For each regression line that I fit, I calculated

Table 2: Congruence Score, Regression Line, $\mathrm{R}^{2}$ Value, and Variance Calculated for Abortion Policy Restrictiveness Related to Abortion Attitude: All States

\begin{tabular}{|c|c|c|c|c|}
\hline State Grouping & $\begin{array}{c}\text { Congruence } \\
\text { Score }\end{array}$ & $\begin{array}{c}\text { Regression } \\
\text { Equation }\end{array}$ & $\mathbf{R}^{\mathbf{2}}$ & Variance \\
\hline All States & 8.18 & $\mathrm{y}=2.0699 \mathrm{x}-0.3382$ & 0.5506 & 0.0392 \\
\hline
\end{tabular}

Note: Under my methodology, a perfect congruence score is $0 . \mathrm{R}^{2}$ exceeding 0.3 is strong. 
Figure 2. Regression: State Abortion Policy Restrictiveness and State Abortion Attitudes (All States)

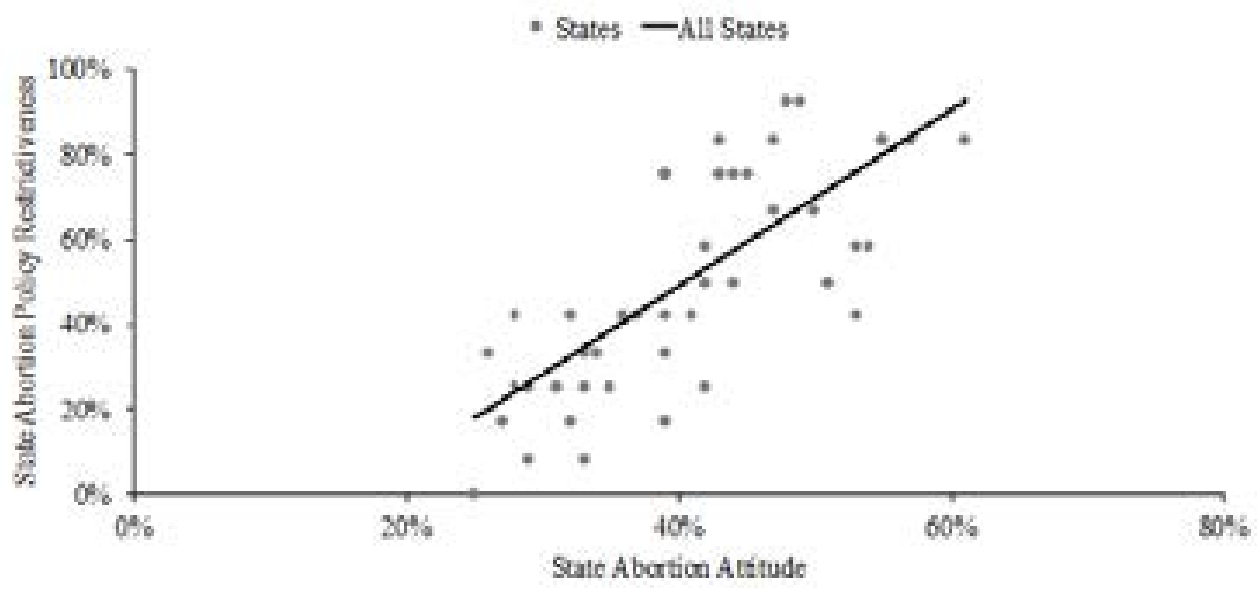

its associated coefficient of determination $\left(\mathrm{R}^{2}\right)$, which is a statistical measure indicating how much variation in the dependent variable (restrictiveness) is explained by variation in the independent variable (attitude). I did not use this statistic to assume that change in the attitude variable causes a change in the restrictiveness variable. Where, however, there is a moderate to high percentage of variation explained by the attitude measure, a case may be made that there is a corresponding level of congruency in the relationship between the variables.

\section{Statistical Variance}

As a final test, I calculated statistical variances for measures of both at- titude and restrictiveness in all groupings to ascertain dispersion of these observations within the groupings. Variance provides a measure of how data observations distribute themselves about their mean.

Scatter plots, $\mathrm{R}^{2}$ values, and variances for the various category groupings supported the existence of a congruent relationship between abortion attitude and policy restrictiveness. Figure 2 represents a scatter plot and least squares regression line for my calculated attitude to restrictiveness measures for all states; states with and without I/R are represented in this data grouping. The positive slope coefficient of the regression line is a logical outcome. That is, as abortion attitudes become more pro-life within a

Table 3: Congruence Score, Regression Line, $\mathrm{R}^{2}$ Value, and Variance Calculated for Abortion Policy Restrictiveness Related to Abortion Attitude: Non-Initiative and Referendum States verses Initiative and Referendum States

\begin{tabular}{|l|c|c|c|c|}
\hline \multicolumn{1}{|c|}{ State Grouping } & $\begin{array}{c}\text { Congruence } \\
\text { Score }\end{array}$ & $\begin{array}{c}\text { Regression Equa- } \\
\text { tion }\end{array}$ & $\mathbf{R}^{2}$ & Variance \\
\hline $\begin{array}{l}\text { Non-Initiative and Refer- } \\
\text { endum States }\end{array}$ & 8.52 & $\mathrm{y}=1.8581 \mathrm{x}-0.2599$ & 0.4544 & 0.0376 \\
\hline $\begin{array}{l}\text { Initiative and Referendum } \\
\text { States }\end{array}$ & 7.09 & $\mathrm{y}=2.302 \mathrm{x}-0.4282$ & 0.6616 & 0.0412 \\
\hline
\end{tabular}

Note: Under my methodology, a perfect congruence score is $0 . \mathrm{R}^{2}$ exceeding 0.3 is strong. 
Figure 3. Regression: State Abortion Policy Restrictiveness and State Abortion Attitude (Initiative and Referendum States and Non-Initiative and Referendum States)

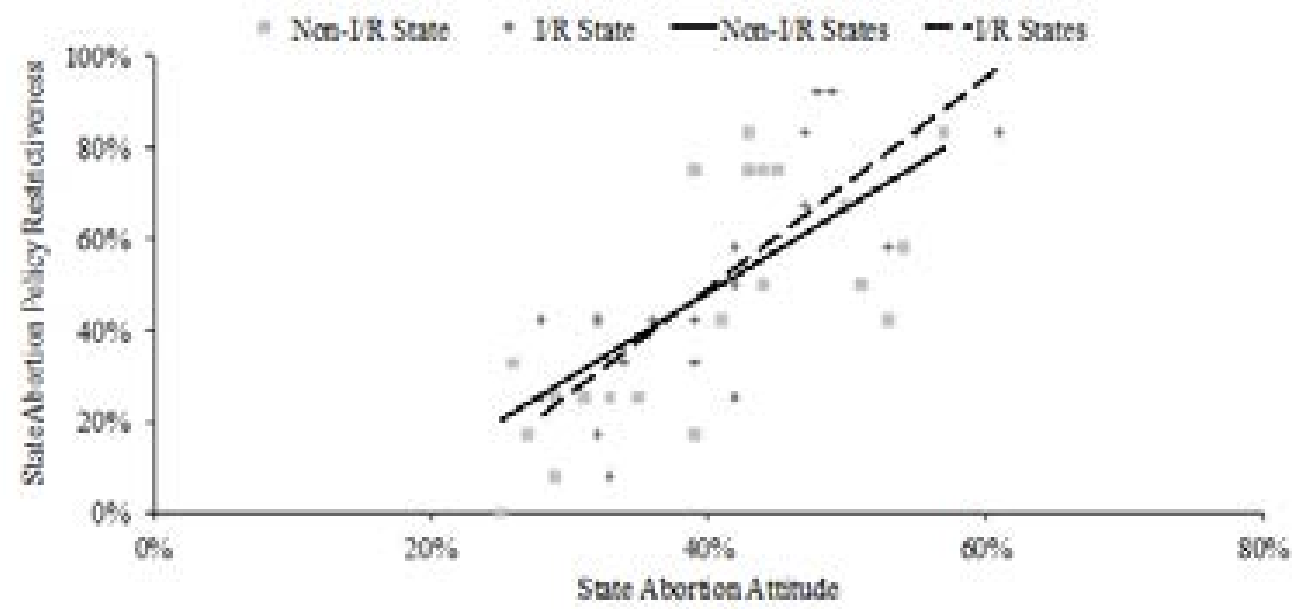

state, policy enactments by the state legislature become more restrictive. As seen in Figure 2 above, as well as in the Table 2 summary, the relatively steep positive slope, the tight dispersion around the regression line, a high $\mathrm{R}^{2}$ value, and the low variance measure, when taken together, strengthen the hypothesis that overall state governments are responsive to their citizens' views on abortion matters.

Non-Initiative \& Referendum States Compared to Initiative \& Referendum States

Scatter plots and regression lines for attitude and restrictiveness observa- tions calculated in both $\mathrm{I} / \mathrm{R}$ and non-I/R states are included in Figure 3. Again, the expected positive slope coefficients exist. Interestingly, the I/R observations produced a slightly steeper positive slope than that demonstrated by the non-I/R observations. This indicated that I/R states have a slightly greater percentage restrictiveness change for each percentage change in attitude. Interpreted another way, responsiveness may be more sensitive to changes in abortion attitude in $\mathrm{I} / \mathrm{R}$ states than in non-I/R states. As summarized in Table 3, a tighter dispersion of observations along the regression line and higher $\mathrm{R}^{2}$ value

Table 4: Congruence Score, Regression Line, $\mathrm{R}^{2}$ Value, and Variance Calculated for Abortion Policy Restrictiveness Related to Abortion Attitude for Easy Implementation Initiative and Referendum States' and Difficult Implementation Initiative and Referendum States' Abortion Policy Restrictiveness and Abortion Attitude

\begin{tabular}{|l|c|c|c|c|}
\hline \multicolumn{1}{|c|}{ State Grouping } & $\begin{array}{c}\text { Congruence } \\
\text { Score }\end{array}$ & $\begin{array}{c}\text { Regression Equa- } \\
\text { tion }\end{array}$ & $\mathbf{R}^{2}$ & Variance \\
\hline $\begin{array}{l}\text { Easy Implementation } \\
\text { Initiative and Referen- } \\
\text { dum States }\end{array}$ & 6.89 & $\mathrm{y}=2.783 \mathrm{x}-0.6103$ & 0.7667 & 0.0654 \\
\hline $\begin{array}{l}\text { Difficult Implementation } \\
\text { Initiative and Referen- } \\
\text { dum States }\end{array}$ & 7.21 & $\mathrm{y}=1.8413 \mathrm{x}-0.2429$ & 0.5644 & 0.0292 \\
\hline
\end{tabular}

Note: Under my methodology, a perfect congruence score is $0 . \mathrm{R}^{2}$ exceeding 0.3 is strong. 
Figure 4: Regression: State Abortion Policy Restrictiveness and State Abortion Attitude (Easy and Difficult Implementation States)

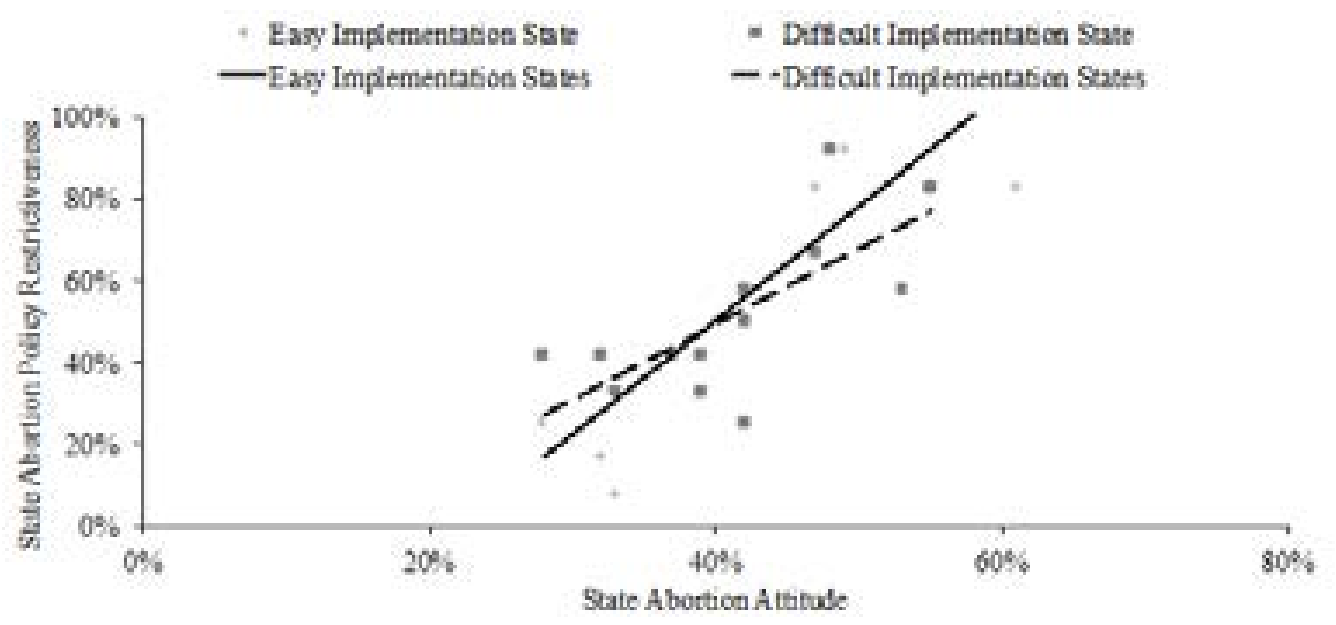

were seen for the I/R states grouping; however, the I/R states demonstrated a somewhat higher variance than that calculated for the non-I/R grouping.

Easy and Difficult Implementation States with Initiative and Referendum

In Figure 4, attitude and restrictiveness scatter plots and regression lines are shown for both easy and difficult implementation I/R states. The implementation groupings contained fewer observations than others. However, similar to my earlier findings, these plots showed positive slope coefficients; that is, an increasing restrictiveness percentage with increasing pro-life attitude percentage. The easy implementation I/R states regression line showed the steepest slope of those plotted, which provides evidence to suggest that states with easy implementation mechanisms for I/R are more likely to demonstrate faster, stronger responses to citizen opinion. Table 4 summarizes the various statistical measures used to analyze each subgrouping. The high $\mathrm{R}^{2}$ value (0.7667) for the easy implementation I/R subgroup is evidence of a strong, positive attitude-restrictiveness congruence for these direct democracy states. On the other hand, the higher statistical vari- ance calculated for the easy implementation subgroup indicated a wider dispersion of observed values than those found for the difficult implementation states.

Congruence scores, slope coefficients, $\mathrm{R}^{2}$ values, and variances for all state observation groupings are summarized in Table 5. Potentially reinforcing the direct democracy responsiveness argument, the easy implementation I/R states grouping demonstrated the steepest slope and highest accounted for variation when associating abortion attitude to policy restrictiveness of all subgroups, even though it demonstrated the highest overall variance among observations.

\section{Conclusions}

Regarding abortion, there appeared to be a noticeable congruence between state legislative response and state citizen attitudes. The congruence scores showed closer policy-opinion alignment across all state direct democracy subgroups. As expected, the easy implementation I/R states subgroup demonstrated the closest congruence between policy restrictiveness and public opinion of all groups calculated. This closer alignment may signify a tendency toward more responsive actions by legislatures to public 
Table 5: Summary Congruence Scores, Regression Lines, $\mathrm{R}^{2}$ Values, and Variances Calculated for the State Sub-Groupings

\begin{tabular}{|l|c|c|c|c|}
\hline \multicolumn{1}{|c|}{ State Grouping } & $\begin{array}{c}\text { Congruence } \\
\text { Score }\end{array}$ & $\begin{array}{c}\text { Regression Equa- } \\
\text { tion }\end{array}$ & $\mathbf{R}^{\mathbf{2}}$ & Variance \\
\hline All States & 8.18 & $\mathrm{y}=2.0699 \mathrm{x}-0.3382$ & 0.5506 & 0.0392 \\
\hline $\begin{array}{l}\text { Non-Initiative and Refer- } \\
\text { endum States }\end{array}$ & 8.52 & $\mathrm{y}=1.8581 \mathrm{x}-0.2599$ & 0.4544 & 0.0376 \\
\hline $\begin{array}{l}\text { Initiative and Referendum } \\
\text { States }\end{array}$ & 7.09 & $\mathrm{y}=2.302 \mathrm{x}-0.4282$ & 0.6616 & 0.0412 \\
\hline $\begin{array}{l}\text { Easy Implementation } \\
\text { Initiative and Referendum } \\
\text { States }\end{array}$ & 6.89 & $\mathrm{y}=2.783 \mathrm{x}-0.6103$ & 0.7667 & 0.0654 \\
\hline $\begin{array}{l}\text { Difficult Implementation } \\
\text { Initiative and Referendum } \\
\text { States }\end{array}$ & 7.21 & $\mathrm{y}=1.8413 \mathrm{x}-0.2429$ & 0.5644 & 0.0292 \\
\hline
\end{tabular}

Note: Under my methodology, a perfect congruence score is $0 . \mathrm{R}^{2}$ exceeding 0.3 is strong.

opinion where easy implementation mechanisms exist.

Regression results all revealed positive slope coefficients. The accompanying statistics also demonstrated moderately high accounted for variations between attitude and restrictiveness variables and low variances for each subgroup. It appears that increasing pro-life opinions within a state may lead to more restrictive, and thus more responsive, policy measures. There are clearer distinctions between I/R and non-I/R states on the relationship of abortion opinion to abortion policy restrictiveness:

1. The highest $\mathrm{R}^{2}$ values were found in the state subgroups with I/R mechanisms. These values were strong and thus accounted for a measurable portion of the variation in restrictiveness related to public opinion. This indicated higher overall congruence between abortion opinion and policy for these direct democracy states.
2. The steepest regression slopes were seen for easy implementation I/R and total I/R states groupings. This indicated more proactive legislative reactions based on opinion variations in these direct democracy states.

3. Non-I/R states demonstrated both less correlation and less steep regression slopes than their direct democracy counterparts. Thus, in non-I/R states, changes in abortion opinion accounted for less of the variability in policy restrictiveness; the rates of change in restrictiveness responses were also less acute.

4. As a group, easy implementation I/R states had a higher $\mathrm{R}^{2}$ value and a steeper regression line slope than those seen for difficult implementation I/R states. These measures indicated greater responsiveness in direct 
democracy states with easier implementation procedures.

5. Difficult implementation I/R states were quite similar to non-I/R states in both regression slope coefficients and calculated variances; this indicated that those states with difficult-to-meet criteria for placing the initiative on the ballot were no different in their policy restrictiveness responses to public opinion than states without direct democracy mechanisms.

These results support the conclusion that there is stronger responsiveness to public opinion in direct democracy states as contrasted to those with no I/R procedures. My hypothesis that there is a measurable difference between $\mathrm{I} / \mathrm{R}$ and non-I/R states as measured by abortion attitudes is thus supported. Additionally, my hypothesis that there is a divergence in policy responses between easy and difficult implementation I/R states is also supported.

My findings and conclusions align with those of Matsusaka, Arceneaux, Lupia, and Gerber, who found that policies in $\mathrm{I} / \mathrm{R}$ states are more responsive to public opinion than those in non-I/R states (Arceneaux 2002; Gerber 1996; Lupia and Matsusaka 2004; Matsusaka 2005, 2010). My work is also consistent with the empirical results of Page and Shapiro, who deduce that highly salient issues, such as abortion, are highly congruent with state public policy (Page and Shapiro 1983). With regards to the distinction in the responsiveness of state abortion policy to public opinion between I/R states with easy and difficult implementation, my conclusions also support those of Bowler and Donovan, who find that easy implementation leads to a stronger correlation between state public policy and public opinion (Bowler and Donovan 2004).
However, my findings are not consistent with those of Lascher Jr., Hagan, Rochlin, and Camobreco, whose research did not find significant effects of direct democracy on the responsiveness of state policy to public opinion (Camobreco 1998; Hagen et al. 2001; Lascher et al. 1996).

\section{Limitations}

This analysis contains several limitations that are worth addressing. The SurveyUSA is arguably the weakest point in the data set. It may not have reflected a comprehensive measure of state abortion attitude because it provided survey respondents only three possible choices: pro-life, pro-choice, and not sure. Past researchers have used data available through the General Social Survey and the American National Election Studies surveys, which pose a wide range of questions about abortion policy. Unfortunately, results from these surveys are publicly reported only at the nation-level. More recent research efforts exploring state responsiveness to public opinion also do not explicitly report state-level data (Matsusaka 2010). The latest available data broken down by state is from 1974 to 1998 (Arceneaux 2002; Brace, Sims-Butler, Arceneaux, and Johnson 2002). Although the state abortion attitude data is only representative of one year, I do not believe this was a problem, as public abortion attitude has remained consistent over the past two decades (Fiorina et al. 2010).

An additional limitation is the less comprehensive nature of my bivariate regression analysis. Both the independent variable, abortion attitude, and dependent variable, policy restrictiveness, could be related to other unknown variables, which may account for some of the variation explained. Further, the relationship displayed could be the result of chance correlation. Nevertheless, I do not believe that either of these limitations significantly influences the outcome of the analysis, as my findings and conclusions match those of other leading 
researchers (Arceneaux 2002; Gerber 1996; Matsusaka 2005; Matsusaka 2010).

\section{Conclusions}

As recent research indicates, states are not polarized in their citizens' views on abortion, and it is difficult to obtain a reliable overall view of public sentiment. In the past decade, American public opinion on abortion has stabilized with fewer groups at the extreme ends of the opinion spectrum. Voters have become increasingly pro-choice, and the labels pro-life and pro-choice may no longer capture the public's true feelings on abortion. There is little variance of opinion between regions, religions, party identifications, gender, or political ideology (Fiorina et al. 2010).
I believe that this empirical research adds to the body of research concerning direct democracy and the responsiveness of state policy to public opinion, especially in relation to abortion; however, it is hard to distinguish whether my findings and conclusions can be compared to past studies since the American public opinion on abortion has stabilized (Fiorina et al. 2010). Of the 10 abortion measures put on the ballot through direct democracy from 2000 to 2013, citizens have only approved three of these ballot measures (Ballotpedia 2014). This leads to a plausible conclusion that public policy on abortion may remain stable as voters continue to deny ballot measures regarding further legislative tampering. Such circumstances could be the subject of further research and scholarly inquiry. 


\section{Appendix 1: State Abortion Policy Restrictiveness}

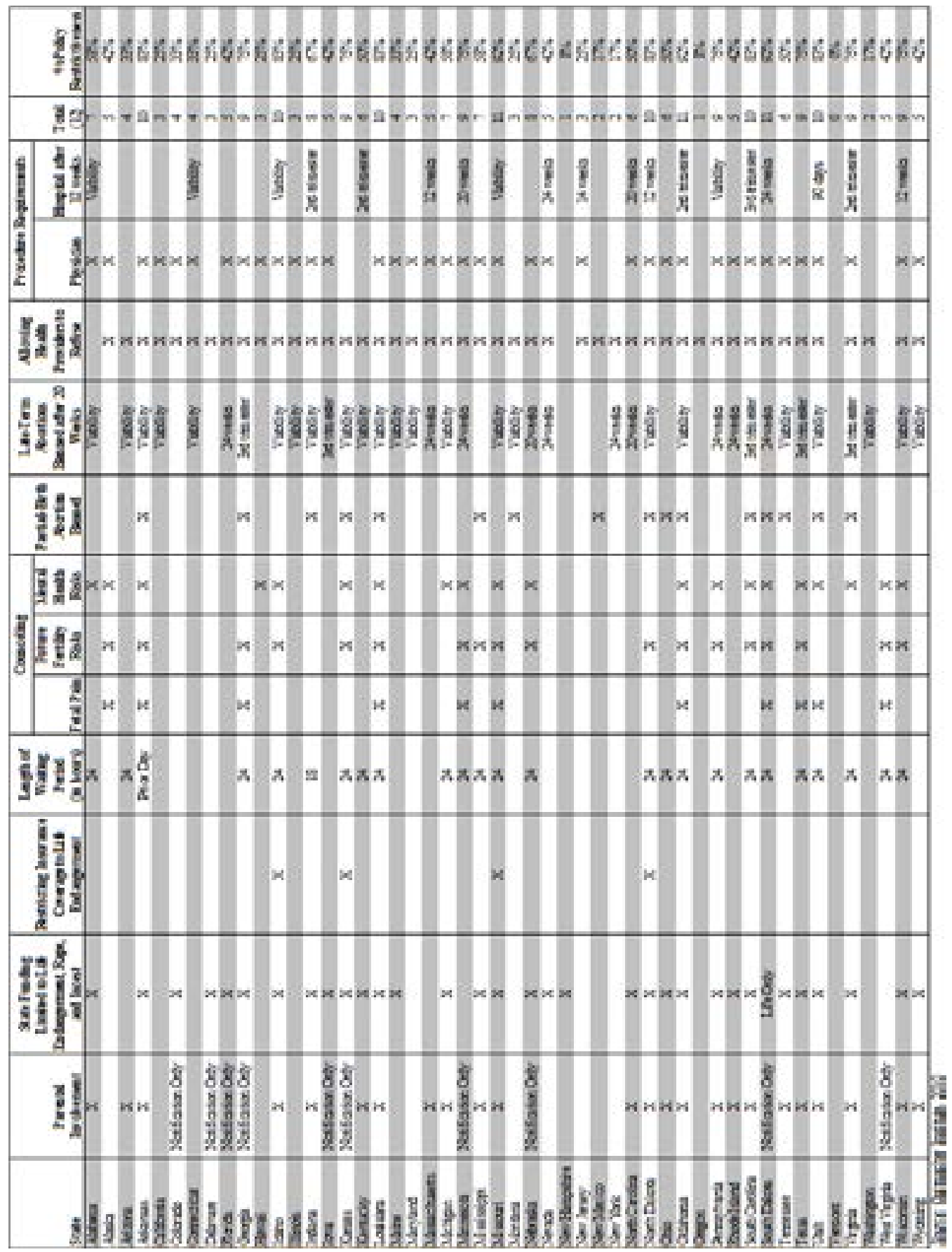


Appendix 2: Implementation Difficulty Index for Initiative and Referendum States

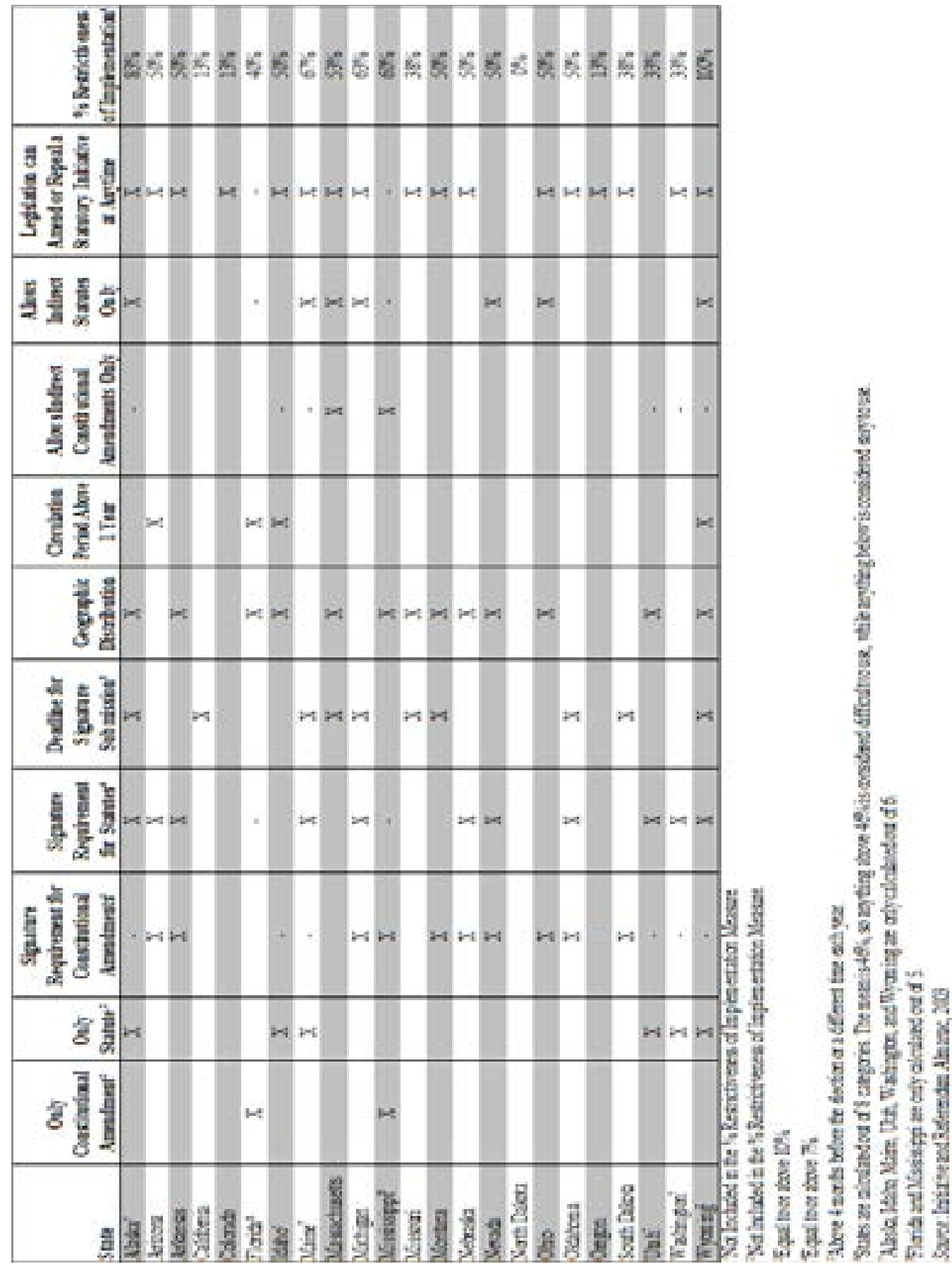




\section{References}

Arceneaux, Kevin. 2002. "Direct Democracy and the Link Between Public Opinion and State Abortion Policy." State Politics \& Policy Quarterly 2, no. 4: 372-387.

Ballotpedia. 2014. "Ballot measures." Wikimedia. Last Modified March 17, 2014. ballotpedia.org/wiki/index.php/Ballot_Measures

Bowler, Shaun, and Todd Donovan. 2004. "Measuring the Effect of Direct Democracy on State Policy: Not All Initiatives are Created Equal.” State Politics \& Policy Quarterly 4, no. 3: 345-363.

Brace, Paul, Kellie Sims-Butler, Kevin Arceneaux, and Martin Johnson. 2002. "Public Opinion in the American States: New Perspectives Using National Survey Data." American Journal of Political Science: 173-189.

Camobreco, John F. 1998. "Preferences, Fiscal Policies, and the Initiative Process." The Journal of Politics 60, no. 03: 819-829.

Erikson, Robert S., Gerald C. Wright and John P. McIver. 1993 Statehouse Democracy: Public Opinion and Policy in the American States. New York, NY: Cambridge University Press.

Ernst, Howard R. 2001. "The Historical Role of Narrow-Material Interests in Initiative Politics." In Dangerous Democracy?: The Battle Over Ballot Initiatives in America, edited by Larry J. Sabato, Howard R. Ernst, and Bruce A. Larson, 1-26. Lanham, MD: Rowan \& Littlefield Publishers, Inc..

Fiorina, Morris P., Samuel J. Abrams, and Jeremy C. Pope. 2010. Culture War?: The Myth of a Polarized America. London, England: Longman Publishing Group.

Gerber, Elisabeth R. 1996. "Legislative Response to the Threat of Popular Initiatives." American Journal of Political Science 40, no. 1: 99-128.

Hagen, Michael G., Edward L. Lascher, and John F. Camobreco. 2001. "Response to Matsusaka: Estimating the Effect of Ballot Initiatives on Policy Responsiveness." The Journal of Politics 63, no. 4: 1257-1263.

Lascher, Edward L., Michael G. Hagen, and Steven A. Rochlin. 1996. "Gun Behind the Door?: Ballot Initiatives, State Policies and Public Opinion.” The Journal of Politics 58, no. 3: 760-775.

Lupia, Arthur. 2001. "Dumber Than Chimps?: An Assessment of Direct Democracy Voters.” In Dangerous Democracy?: The Battle Over Ballot Initiatives in America, edited by Larry J. Sabato, Howard R. Ernst, and Bruce A. Larson, 6670. Lanham, MD: Rowan \& Littlefield Publishers, Inc.

Lupia, Arthur, and John G. Matsusaka. 2004. "Direct Democracy: New Approaches to Old Questions." Annual Review of Political Science 7: 463-482.

Matsusaka, John G. 2001. "Problems with a Methodology Used to Evaluate the Voter Initiative." The Journal of Politics 63, no. 4: 1250-1256.

. 2005. "Direct Democracy Works." The Journal of Economic Perspectives 19, no. 2: 185-206.

. 2010. "Popular Control of Public Policy: A Quantitative Approach." Quarterly Journal of Political Science 5: 133-167.

Mooney, Christopher Z., and Mei-Hsien Lee. 1995. "Legislative Morality in the American States: The Case of Pre-Roe Abortion Regulation Reform.” American Journal of Political Science 39, no. 3: 599-627.

Page, Benjamin I., and Robert Y. Shapiro. 1983. "Effects of Public Opinion on Policy." The American Political Science Review 77, no. 1: 175-190.

Saari, Donald G. 2001. "The Sum of the Parts Can Violate the Whole." The American Political Science Review 95, no. 2: 415-433. 
SurveyUSA. 2005. "Pro-Life vs. Pro-Choice". Verona, NJ: Survey USA. www.surveyusa. com/50State2005/50StateAbortiono805SortedbyState.htm

Guttmacher Institute. State Policies in Brief: An Overview of Abortion Law. 2010.

New York, NY: Guttmacher Institute. Last Modified April 1, 2014. http://www. guttmacher.org/statecenter/spibs/spib_OAL.pdf

Walters, M. Dane. 2003. Initiative and Referendum Almanac. Durham, NC: Carolina Academic Press.

Samantha E. Holquist is a second year Master of Public Administration student at the George Washington University, concentrating in program evaluation and education policy. She earned a BA in political science and religious studies from Wake Forest University in 2011. Prior to graduate studies, Samantha worked for the Public Religion Research Institute and conducted statistical analyses on American public opinion survey data concerning attitudes toward domestic policies. Currently, she works for District of Columbia Public Schools and plans on dedicating her career to improving the quality of education provided to America's students.

The author would like to thank Brandon Kruse, Tanya Harris Joshua, and Mathew Vicknair for their support and time dedicated to editing her paper. She also thanks Professor David Brunori for his feedback and direction throughout the editing process. She is indebted to Dr. John Dinan for providing her with the initial inspiration to undertake the study and for providing critical initial comment and advice. Finally, the author would like to thank her family, particularly Donnie Crandell, for their continuous guidance and encouragement as she pursues her academic and professional goals. 